\title{
Methadone Extraction by Modified Quechers and Liquid-Liquid Extraction from Post-Mortem Urine by GC-MS
}

\section{Seyed Majid Salimi AsI ${ }^{*}$, Mohammad Javad Khodayar ${ }^{2}$, Zahra Mousavi ${ }^{3}$ and Maryam Akhgari ${ }^{4}$}

${ }^{1}$ Department of Toxicology, Pharmaceutical Sciences Branch, Islamic Azad University, Tehran, Iran

2Department of Toxicology, School of Pharmacy, Ahvaz Jundishapur University of medical Sciences, Ahvaz, Iran

${ }^{3}$ Department of Pharmacology-Toxicology, Faculty of Pharmacy, Pharmaceutical Sciences Branch, Islamic Azad University, Tehran, Iran (IAUPS)

${ }^{4}$ Department of Forensic Toxicology, Legal Medicine Research Center, Legal Medicine Organization, Tehran, Iran

*Corresponding author: Seyed Majid Salimi Asl, Department of Toxicology, Pharmaceutical Sciences Branch, Islamic Azad University, Tehran, Iran, Tel: 00989166172584; E-mail: majid.salimi2012@yahoo.com

Received date: November 06, 2017; Accepted date: December 04, 2017; Published date: December 11, 2017

Copyright: (C2017 Asl SMS, et al. This is an open-access article distributed under the terms of the Creative Commons Attribution License, which permits unrestricted use, distribution, and reproduction in any medium, provided the original author and source are credited

Citation: AsI SMS, Khodayar MJ, Mousavi Z, Akhgari M (2017) Methadone Extraction by Modified Quechers and Liquid-Liquid Extraction from PostMortem Urine by GC-MS. J Med Toxicol Clin Forensic Med. Vol.3 No.2:10

\section{Abstract}

Background: Methadone abuse in drug addiction centers and increased methadone consumption among addicts is a new cause of mortality due to substance abuse in forensic medicine. The usual method of extracting urine from corpses in most legal centers is a long and costly method of liquid-liquid extraction, which in addition to the high consumption of solvents and environmental contamination causes severe damage to the column of laboratory analysis devices. As a result, QuEChERS extraction method was proposed as an easy, fast, cheap and green way.

Objective: In this paper, the results of methadone extracted from the urine after death using Liquid-Liquid extraction and modified QuEChERS method were compared.

Method: Liquid-liquid extraction (LLE) by acidifying the urine sample with $\mathrm{Hcl}$ and separating the organic phase at an alkaline $\mathrm{pH}$, with a Chloroform and Isopropanol solvent. Extraction in the QuEChERS method is using $\mathrm{MgSO}_{4}$ and $\mathrm{NaCl}$ salts and ethyl acetate solvent. Detect methadone in two methods with GC-MS.

Results: The recovery level of methadone of urine sample was obtained equal to 78\% ( $\mathrm{N}=15)$ in QuEChERS method and equal to $55 \%(\mathrm{~N}=15)$ in LLE method. According to the obtained results, there was significant difference between QUEChERS and LLE methods in the term of methadone test in post-mortem urine.

Conclusion: Cheap, fast, effective and green QuEChERS improved with better recovery could replace the LLE method in detecting methadone in post-mortem urine samples.
Keywords: LLE; QuEChERS; Methadone; Post-mortem urine; GC-MS

\section{Introduction}

QuEChERS stands for Quick, Easy, Cheap, Effective, Rugged and Safe. Alves et al. [1] first introduced this method to extract veterinary drugs from animal tissue. This method is widely used to determine pesticides [1]. In forensic medicine are usually use Liquid-Liquid extraction (LLE) and solid phase extraction (SPE) methods. The SPE method is expensive and the cleaning of the homogenizer probe creates a risk of contamination and crossreactivity, and therefore the SPE method is somewhat tedious and time-consuming and cannot be performed in many centers, but the QuEChERS method is widely used as a simple, fast and reliable method is used [2]. Extraction is an important step in the analysis of toxicology in forensic medicine [3,4]. Clinical toxicology and forensic medicine are heavily dependent on the science of decomposition chemistry $[5,6]$. Liquid-liquid extraction is simple but reduces its value due to inadequate extraction of samples and contamination of tools and the environment. The SPE method with a high selective performance, but this method is relatively costly and timeconsuming. The QuEChERS method was proposed for the analysis of legal toxicology [7]. The QuEChERS method is similar to LLE is simple and also similar to SPE have high selective performance $[7,8]$. The QuEChERS method is used to determine the residue of pesticides in food products $[7,9]$. QuEChERS is based on extraction with solvents such as acetonitrile or ethyl acetate and dehydration in the presence of salts such as magnesium sulfate and sodium chloride. Methadone is predominantly prescribed for treatment of heroin addiction and has a morphine-like function [10]. Some methadone is metabolized to the 2-Ethylidene-1,5-dimethyl-3,3diphenylpyrrolidine (EDDP) by Cytochrome P450 (CYP3A4). The ratio EDDP to Methadone is used in the diagnosis of long-term 
and short-term treatment [11]. However, EDDP is the product of the side effect of high temperature GC on methadone. Reducing the temperature of the $\mathrm{GC}$ inlet port from 260 to $180^{\circ} \mathrm{C}$ reduced the concentration of EDDP observed in a methadone sample at an initial concentration of $10,000 \mathrm{ng} / \mathrm{mL}$ from $201 \mathrm{ng} / \mathrm{mL}$ to 53 $\mathrm{ng} / \mathrm{mL}$. As a result, alternative methods such as HPLC or LC-MS should be considered [12].

In this paper, Methadone extraction by QuEChERS from postmortem urine samples.

\section{Materials and Method}

The Methadone (ST) with concentration of $100 \mu \mathrm{g} / \mathrm{mL}$ (Sigmaal Rich), Methanol, Ammonia, Chloroform, Isopropanol, Acid hydrochloric acid, Ethyl acetate, Magnesium sulfate, Sodium hydrogen chloride (Figure 1).

\begin{tabular}{|c|}
\hline 25mL urine $+25 \mathrm{~mL} \mathrm{Hcl}($ water bath $60 \mathrm{~min})$ \\
\hline Add 50cc solvent chloroform and isopropanol (3 to 1 ratio), mixed ( $15-20 \mathrm{~min}$ ) \\
\hline $\begin{array}{c}\text { Separating the organic part of the mixture by decanter, collect and dry and dissolve in } \\
500 \mu \mathrm{l} \text { methanol and inject } 1 \mu \mathrm{l} \text { in GC-MS }\end{array}$
\end{tabular}

Figure 1 Liquid-liquid extraction method.

\begin{tabular}{|c|}
\hline $1 \mathrm{~mL}$ urine $+1 \mathrm{~mL} \mathrm{Hcl} 50 \%$ (v/v), in water bath $(60 \mathrm{~min})$ \\
\hline $1 \mathrm{~mL}($ falcon tube $15 \mathrm{~mL})+500 \mu \mathrm{L} \mathrm{DW}, 200 \mu \mathrm{L}$ of $\mathrm{NH} 32 \mathrm{M}(\mathrm{pH}=8-9)$ \\
\hline Vortex (10 seconds) +centrifuge $5000 \mathrm{~g}(3 \mathrm{~min})$ \\
\hline QuEChERS extract powder $(400 \mathrm{mg} \mathrm{MgSO}$ and $200 \mathrm{mg} \mathrm{NaCl})+1000 \mu \mathrm{l}$ of ethyl acetate \\
\hline Mixed (10 seconds) + centrifuge $8000 \mathrm{~g}(5 \mathrm{~min})$ \\
\hline Dehydration step: Liquid dissociation +100 mg MgSO 4 \\
\hline Mixed (10 seconds) + centrifuge $3000 \mathrm{~g}(2 \mathrm{~min})$ \\
\hline $\begin{array}{l}\text { Isolation of supernatant in a glass vial and drying with nitrogen at room temperature + Dissolve in } \\
\qquad 500 \mu \mathrm{L} \text { methanol and } 1 \mu \mathrm{L} \text { injection in GC-MS }\end{array}$ \\
\hline
\end{tabular}

Figure 2 QuEChERS method.

The oven temperature increased from $60^{\circ} \mathrm{C}$ to $280^{\circ} \mathrm{C}$ at a Helium gas was used with a purity of $999 / 99$ at a flow rate of 1 temperature of $10^{\circ} \mathrm{C}$ and was kept constant at $280^{\circ} \mathrm{C}$ for $10 \mathrm{~min}$. $\mathrm{mL} / \mathrm{min}$ and a mass energy of 70 ev. Split less injection mode 
and run time is $30 \mathrm{~min}$. The methadone identification method was based on the SIM index ion (Table 1).

Table 1 Index ions in GC-MS.

\begin{tabular}{|l|l|l|l|}
\hline Analyte & Quantifier $(\mathbf{m} / \mathbf{z})$ & Qualifier $(\mathbf{m} / \mathbf{z})$ & RT \\
\hline Methadone & 72 & 294223165 & 11.7 \\
\hline EDDP & 276 & 262220165 & 11.1 \\
\hline
\end{tabular}

For analysis of the Gas chromatography apparatus model 7890A connected to Agilent mass spectrometer Model 5975C equipped with a column $\left(30 \mathrm{~m}^{*} 0.25 \mathrm{~mm}^{*} 0.25 \mu \mathrm{m}\right.$ thin film thickness), which used as a fixed phase with $5 \%$ phenyl methyl (Figure 2).

The results were analyzed with the Wiley7n.1 library software GC-MS according to the index $(\mathrm{m} / \mathrm{z})$ (Figure 3). Methadone validation and its results in Table 2.

Table 2 methadone validation and its results.

\begin{tabular}{|c|c|c|c|c|c|c|}
\hline Accuracy $(\%, n=3)$ & Precision $(\%, n=3)$ & Quality control Concentration $(\mathrm{ng} / \mathrm{mL})$ & $\mathrm{LOQ}(\mathrm{ng} / \mathrm{mL})$ & LOD (ng/mL) & $\mathrm{N}=3$ & \\
\hline 89 & 13.5 & 62.5 & & & Day $=1$ & \\
\hline 95 & 8 & 250 & 97.3 & 29.1 & Day $=2$ & Methadone \\
\hline 101 & 11 & 2000 & & & Day $=3$ & \\
\hline
\end{tabular}

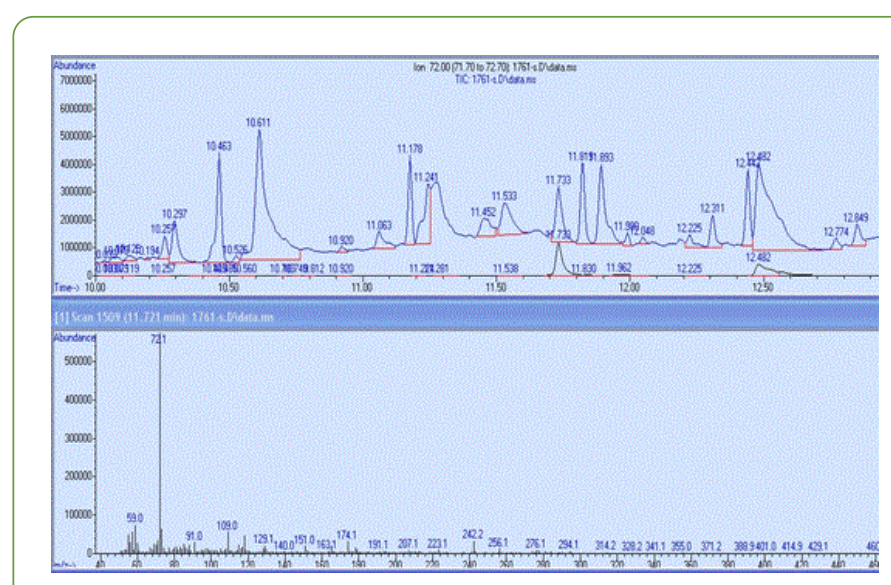

Figure 3 Methadone analysis based on index ion in GC-MS.

\section{Results}

Methadone recovery rates in different samples in QuEChERS method were $65-78 \%$ (Figure 4). Generally, the rate of recovery in studies is between $80 \%$ and $120 \%$ (Figure 5). Jones et al. showed that for QuEChERS, 60-70\% improvement for medium and non-polar compounds is acceptable [13].

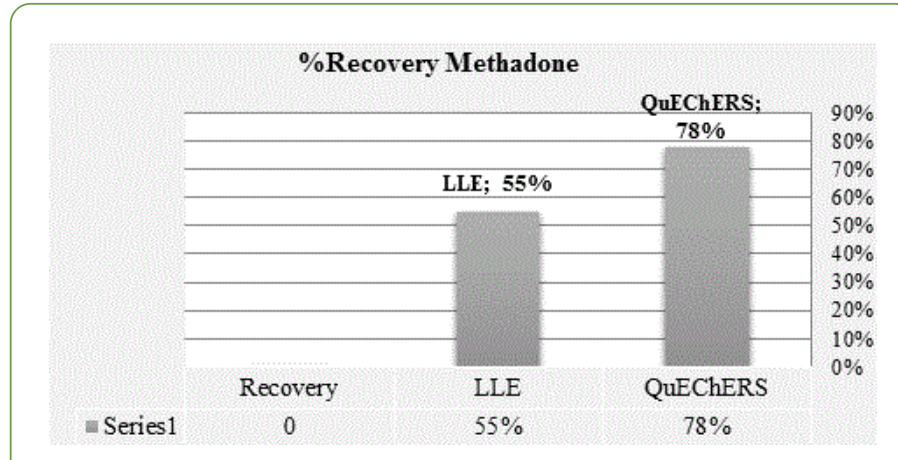

Figure 4 Compare recovery with two extraction methods.

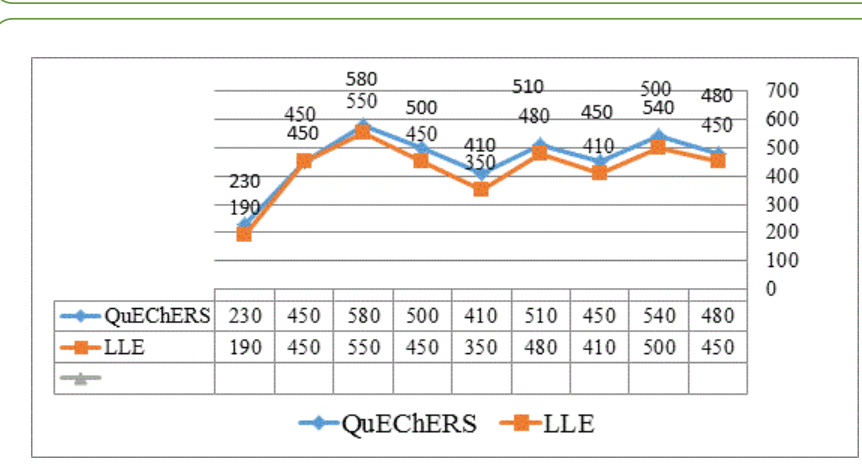

Figure 5 Comparison of methadone levels in Post-mortem urine by two methods of extracting $\mathrm{ng} / \mathrm{ml}$.

\section{Discussion}

Extraction method in most of the forensic centers is LLE. Large volume of samples and solvents, inadequate extraction and contamination of tools and the environment are main disadvantages of LLE method [1]. Compounds of carcinogen and mutagen such as Chloroform and Ammonia, threat to the health of staff and experts in forensic centers. In addition, utilizing large 
amounts of solvent and chemicals seriously threatens the enviroment and human community. As a result, finding an efficient method with fewer risks force us to use new techniques such as SPE and QuEChERS.

QUEChERS was approved as a sensitive, renewable and relatively simple method for qualitative and quantitative analysis of drugs and medicine. Since this method does not require specific equipment and requires less time, this method has a great potential for analyzing clinical and legal samples.A review of the results from previous studies in QuEChERS extraction has proved its ability to detect drugs and drugs in biological samples. In a study by Emanuele Amorin Alves and colleagues in 2016 aimed at refining and developing the QuEChERS method, he was able to detect 13 opioid, methadone, and cocaine and their metabolites in total blood with the GC-MS device, Showed that this method has a high operational capability in various forensic cases [2]. It's easy to detect analyte with varying amounts of detection with a reagent and calculate the highest recovery, but the implementation of these methods is based on actual samples that are metabolized in the body or in samples of corpses that are corrupted after Death is different. There are numerous interventions in these samples, such as binding and conjugation of analyte to vital molecules, Postmortem Redistribution, metabolism, and the formation of secondary metabolites and post-mortem corruption makes it difficult to work. The results were much better in comparison with the LLE method in terms of ease, fastness and low cost.

\section{Conclusion}

The results of this study did not show significant difference betweenthe results of costly and time-consuming LLE method with QuEChERS method. Recovery of methadone in a much smaller volume of urine samples inQuEChERS, Showed that this method could replace LLE in detecting methadone in urine after death.

\section{Financing and support}

The cost of this thesis was completely personalized and with the scientific support of the Department of Toxicology, Faculty of Pharmacy, Jundishapur, Ahvaz, and the Legal Medicine Organization of Khuzestan-Ahvaz Province and the Toxicology Group of the Pharmaceutical Sciences University of Islamic Azad University, Tehran.

\section{Acknowledgement}

Thanks to all my dear professors and friends who helped me with this article.

\section{References}

1. Alves EA, Agonia AS, Cravo SM, Afonso CM, Netto ADP, et al. (2017) GC-MS method for the analysis of thirteen opioids, cocaine and cocaethylene in whole blood based on a modified quechers extraction. Curr Pharm Anal 13: 215-223.

2. Usui K, Hashiyada M, Hayashizaki Y, Yui I, Hosoya T, et al. (2014) Application of modified QuEChERS method to liver samples for forensic toxicological analysis. Forensic Toxicol 32: 139-147.

3. Bogusz MJ (2000) Liquid chromatography-mass spectrometry as a routine method in forensic sciences: A proof of maturity. J Chromatogr B Biomed Sci Appl 748: 3-19.

4. Sauve $E$, Langødegård M, Ekeberg D, Øiestad AM (2012) Determination of benzodiazepines in ante-mortem and postmortem whole blood by solid-supported liquid-liquid extraction and UPLC-MS/MS. J Chromatogr B Analyt Technol Biomed Life Sci 883: $177-188$

5. Dinis-Oliveira RJ, Carvalho F, Duarte JA, Remião F, Marques A (2010) Collection of biological samples in forensic toxicology. Toxicol Mech Methods 20: 363-414.

6. Dinis-Oliveira RJ, Magalhães T (2013) Forensic toxicology in drugfacilitated sexual assault. Toxicol Mech Methods 23: 471-478.

7. Anastassiades M, Lehotay SJ, Stajnbaher D, Schenck FJ (2003) Fast and easy multiresidue method employing acetonitrile extraction/ partitioning and "dispersive solid-phase extraction" for the determination of pesticide residues in produce. J AOAC Int 86: 412-431.

8. Payá P, Anastassiades M, Mack D, Sigalova I, Tasdelen B (2007) Analysis of pesticide residues using the Quick Easy Cheap Effective Rugged and Safe (QuEChERS) pesticide multi-residue method in combination with gas and liquid chromatography and tandem mass spectrometric detection. Anal Bioanal Chem 389: 1697-1714.

9. Lehotay SJ, Son KA, Kwon H, Koesukwiwat U, Fu W (2010) Comparison of QuEChERS sample preparation methods for the analysis of pesticide residues in fruits and vegetables. J Chromatogr A 1217: 2548-2560.

10. Soltaninejad K, Karimi M, Nateghi A, Daraei B (2016) Simultaneous determination of six benzodiazepines in spiked soft drinks by high performance liquid chromatography with ultra violet detection (HPLC-UV). Iran J Pharm Res 15: 457.

11. Ferrari A, Coccia CP, Bertolini A, Sternieri E (2004) Methadonemetabolism, pharmacokinetics and interactions. Pharmacol Res 50: 551-559.

12. George S, Braithwaite RA (1999) A pilot study to determine the usefulness of the urinary excretion of methadone and its primary metabolite (EDDP) as potential markers of compliance in methadone detoxification programs. J Anal Toxicol 23: 81-85.

13. Jones AW, Holmgren A, Kugelberg FC (2008) Driving under the influence of opiates: concentration relationships between morphine, codeine, 6-acetyl morphine and ethyl morphine in blood. J Anal Toxicol 32: 265-272. 